\title{
Measles outbreak linked to insufficient vaccination coverage in Nouvelle-Aquitaine Region, France, October 2017 to July 2018
}

Anne Bernadou ${ }^{1,2}$, Cyril Astrugue1, Matthieu Méchain³, Valérie Le Galliard ${ }^{3}$, Catherine Verdun-Esquer ${ }^{4}$, France Dupuy ${ }^{5}$, Julia Dina6, Fatima Aït-Belghiti', Denise Antona ${ }^{7}$, Stéphanie Vandentorren ${ }^{1}$

1. Santé Publique France, French National Public Health Agency, Regional office in Nouvelle-Aquitaine, Bordeaux, France.

2. European Programme for Intervention Epidemiology Training (EPIET), European Centre for Disease Prevention and Control $(E C D C)$, Stockholm, Sweden

3. Regional health agency in Nouvelle-Aquitaine, Bordeaux, France

4. Occupational medicine service of Bordeaux University hospital, Bordeaux, France

5. Student health service, Bordeaux, France

6. National Reference Center for Measles, Mumps and Rubella, CHU de Caen, Virology Department, Caen, France

7. Santé publique France, French National Public Health Agency, Infectious Diseases Department, Saint-Maurice, France

Correspondence: Anne Bernadou (anne.bernadou@santepubliquefrance.fr)

Citation style for this article:

Bernadou Anne, Astrugue Cyril, Méchain Matthieu, Le Galliard Valérie, Verdun-Esquer Catherine, Dupuy France, Dina Julia, Aït-Belghiti Fatima, Antona Denise, Vandentorren Stéphanie. Measles outbreak linked to insufficient vaccination coverage in Nouvelle-Aquitaine Region, France, October 2017 to July 2018 . Euro

Surveill. 2018;23(30): pii=1800373. https://doi.org/10.2807/1560-7917.ES.2018.23.30.1800373

Article submitted on 05 Jul 2018 / accepted on 26 Jul 2018 / published on 26 Jul 2018

On 30 October 2017, an outbreak of measles started in the Nouvelle-Aquitaine (NA) region in France among Bordeaux University students before spreading to other regions. Until 1 July 2018, 1,101 cases were reported in NA, including 98 complications and two deaths. Cases were related to clusters (e.g. students, healthcare workers) in $16 \% ; 81 \%$ of cases were not vaccinated against measles as recommended. Vaccination coverage above herd immunity threshold remains the main preventative outbreak measure.

On 30 October 2017, a measles outbreak started among students attending Bordeaux University in the southwest of France. It rapidly spread into the general population of Bordeaux's Gironde district, into Nouvelle-Aquitaine region (NA) and then onto other regions. We conducted an investigation to describe the outbreak, identify clusters and stop further transmission.

\section{Case definitions}

In France, measles became a notifiable disease in 2005 to improve the detection of active transmission and increase the specificity of the diagnosis through laboratory confirmation of clinical cases. Clinicians and microbiologists are requested to report suspected and confirmed measles cases immediately to the Regional Health Agencies (ARS) responsible for implementing control measures.

We included all cases reported in the mandatory notification system (possible, probable and confirmed) who lived in NA and developed rash onset between 30
October 2017 and 1 July 2018 (Box). We interviewed cases to identify contacts at risk and detect clusters in high risk groups.

\section{Outbreak description}

In total, 1,101 cases (466 possible, 199 probable, 436 confirmed) were reported in NA which represented $41 \%$ of the cases reported in France. Following the start of the measles outbreak on 30 October 2017, cases increased from week 502017 and peaked during week 132018 (Figure 1). Five hundred and eighty-one cases (53\%) were male, and 646 (59\%) cases were older than 15 years. The highest cumulative incidence rate was observed in children $<1$ year of age $(160.8 / 100,000)$. The incidence rate was 40.7 per 100,000 in children of 1-14 years, 41.7 in young adults of 15-29 years and 4.1 in adult's $\geq 30$ years. Of the 1,101 cases, 248 cases $(23 \%)$ were hospitalised, 98 cases (9\%) had complications and two died - one of respiratory complications (in their mid-30s, with underlying risk factors: morbid obesity and heavy smoking) and the second of neurologic complications (teenager, with an immunodeficiency).

The majority of the 1,101 cases ( $n=617 ; 56 \%$ ) lived in Gironde, which is NA's biggest district; all districts reported cases (Figure 2). In NA, the cumulative crude incidence rate was 18.5 per 100,000 population (vs 4.0/100,000 in France during the same period), and reached 39.4 per 100,000 population in Gironde.

A total of $594(69 \%)$ of 860 cases with a known vaccination status were unvaccinated, 128 (15\%) had 
Definition of cases and other categories followed-up during the measles outbreak, Nouvelle-Aquitaine region, France, 30 October 2017-1 July 2018

\section{Measles cases}

Possible case

Person presenting with fever $\geq 38.5^{\circ} \mathrm{C}$, maculopapular rash and at least one of the following symptoms: conjunctivitis, coryza, cough or Koplik's spots

Probable case

Person meeting the clinical criteria and with an epidemiological link to a laboratory-confirmed case

Confirmed case

Person meeting the clinical criteria and with laboratory-confirmed measles infection detected by serology or RT-PCR in serum or oral fluid and not recently vaccinated

\section{Other categories}

Cluster

At least three cases including one confirmed case in high-risk groups

High-risk groups

Groups with high number of susceptibles and/or people at risk to develop complications

received one dose, 118 (14\%) two doses and 20 (2\%) had been vaccinated with an unspecified number of doses.

Between 30 October 2017 and 1 July 2018 (study period) genotyping was conducted on 125 specimens by the French National Reference Laboratory for Measles in Caen, leading to the identification of genotype D8 in 105 cases (84\%) and genotype $B_{3}$ in 12 cases (10\%). For six specimens the sequencing test was in failure due to limited material.

A total of 176 cases (16\%) were related to clusters (n = 19) (Table 1).

\section{French vaccination schedule}

Measles-containing vaccines have been included in the French vaccination schedule since 1983 with the first dose administered at 12 months of age. In 1996, a second dose was introduced and initially administered at 11 years of age, but changed to 3 to 6 years of age in 1997. This led to a decrease in the number of estimated measles cases (clinical case definition) from 331,000 cases in 1986 to 4,448 cases in 2004 [1]. Despite its increase, vaccination coverage in 2000 remained under the target of $85 \%$ for the first dose. A large outbreak occurred between 2008 and 2011, leading to more than 22,000 reported cases [2]. Since 2005 , two doses of measles, mumps and rubella (MMR) vaccine has been recommended in France; the first dose administered at 12 months of age and the second dose between 16 and 18 months. A two-dose catch-up measles vaccination is recommended for people born in 1980 and after [3].

\section{Control measures}

Specific control measures targeting populations affected by the outbreak were implemented by ARS according to national guidelines, including catch-up and post-exposure vaccination and/or prophylaxis with immunoglobulin for people at high-risk of severe disease [4].

Since December 2017, information regarding the recommended vaccination schedule has been disseminated to the population in NA via various means e.g. newspapers and social media, as well as to health workers (HCWs) and specific at-risk populations such as France nomadic minorities.

Infection control measures such as isolation of cases and airborne precautions were implemented in healthcare facilities and susceptible individuals (unvaccinated HCWs and patients' contacts without history of measles) were vaccinated to reach two doses of MMR vaccine. MMR catch-up campaigns were undertaken targeting the population around several clusters: University students (Bordeaux and Poitiers), HCWs in Bordeaux hospital, places of France's nomadic minorities in Gironde and Vienne districts and the prison in Vienne. The outbreak control team established mobile vaccination teams to increase vaccination uptake among these groups.

\section{Discussion}

Since May 2017, there has been an increase in measles incidence in several Europe countries [5]. France has been experiencing a large measles outbreak that started in NA, rapidly spread to other regions and 


\section{FIGURE 1}

Notified measles cases by week of rash onset, NouvelleAquitaine region, France, 30 October 2017-1 July 2018 $(\mathrm{n}=1,101)$

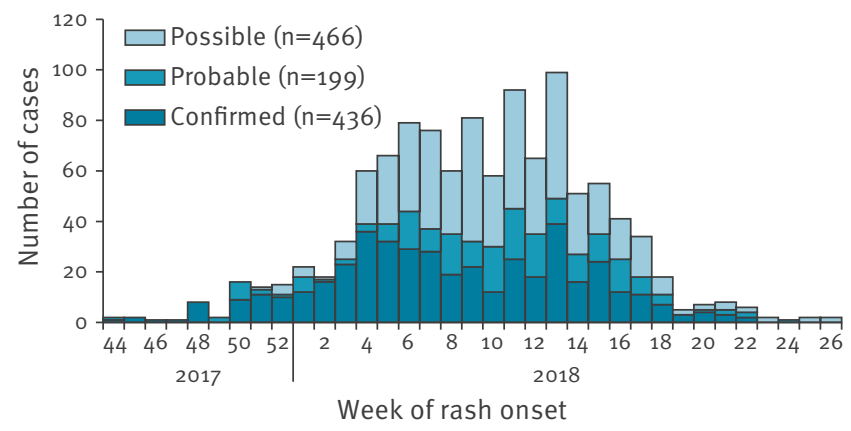

Source: Notification data-Santé publique France.

resulted in a total of 2,663 cases in France between 30 October 2017 to 1 July 2018 [6]; among which 1,101 occurred in NA (41\%) where clusters among undervaccinated groups were documented.

We also observed cases among fully vaccinated people and the proportion of fully vaccinated among cases was higher than what was observed in France during the $2008-11$ epidemic ( $14 \%$ vs $3-4 \%$, respectively). This may be linked to the waning immunity over time among vaccinated people and to a higher proportion of vaccinated cases in a population where the level of vaccination coverage becomes optimal $[2,7,8]$. But this finding should nevertheless be further investigated.

The second MMR dose vaccination coverage administered at 2 years of age increased from $45-64 \%$ in 2010 to $71-81 \%$ in 2015 among the districts of NA; yet it remained insufficient to reach the herd immunity threshold of $95 \%$ to achieve a high level of population immunity and measles elimination $[9,10]$. Vaccination coverage is most likely lower among minority groups such as nomadic minorities or confessional groups, but it would not alone account for the low vaccination coverage of the region; further studies are ongoing to estimate vaccination coverage among France's nomadic minorities.

The main circulating genotypes reported in NA were B3 and D8, as observed in the rest of the country and Europe [11].

Two clusters started among university students, which belong to large cohorts with increasing numbers of under-vaccinated (susceptible) people. Crowded environments with close-contact situations such as those observed in students' communities can greatly contribute to the emergence of outbreaks. Moreover complications are often more frequent and more severe for these age groups [12].

\section{FIGURE 2}

Crude incidence rate of measles, by district, NouvelleAquitaine region, France, 30 October 2017-1 July 2018 $(\mathrm{n}=1,101)$

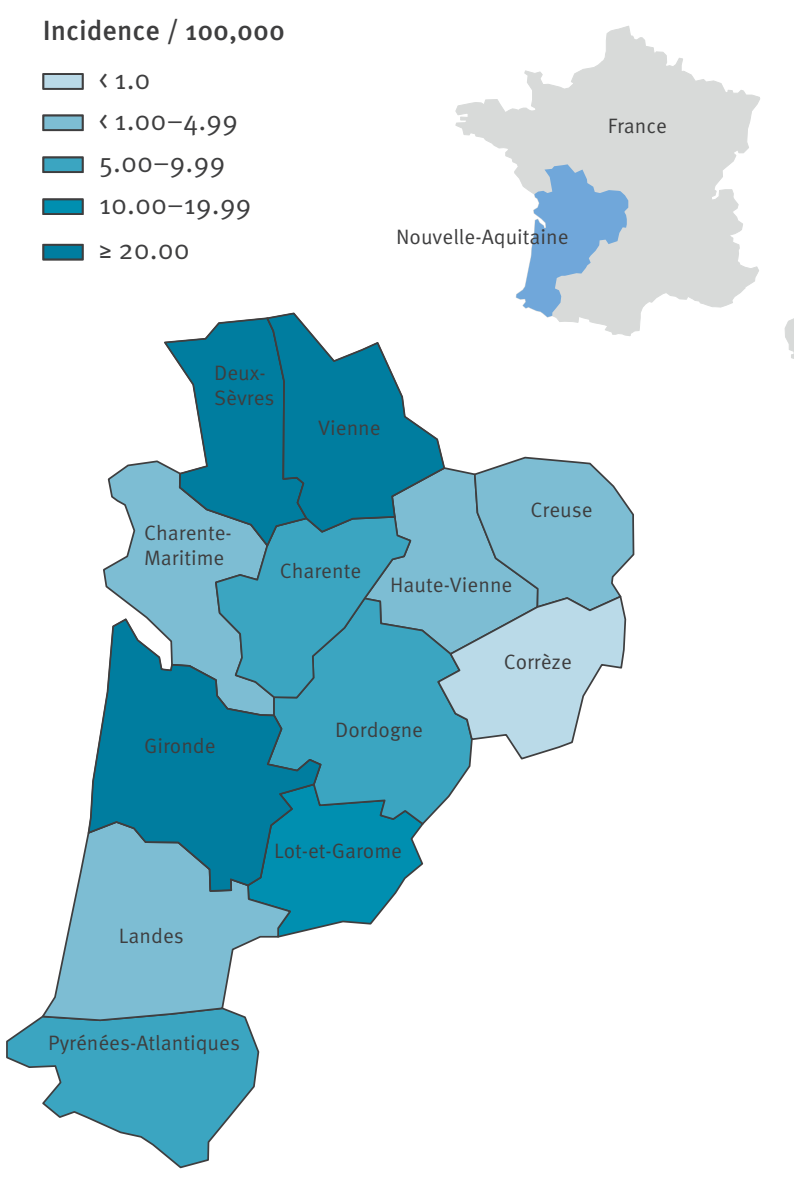

Source: Notification data-Santé publique France, extracted on 23 July 2018.

Number of cases: Charente $(n=18)$, Charente-Maritime $(n=25)$, Corrèze $(n=2)$, Creuse $(n=3)$, Deux-Sèvres $(n=89)$, Dordogne $(n$ $=31)$, Gironde $(n=617)$, Haute-Vienne $(n=14)$, Landes $(n=19)$, Lot-et-Garonne $(n=41)$, Pyrénées-Atlantiques $(n=39)$, Vienne ( $n$ = 203).

Two of the clusters occurred in healthcare facilities involving HCWs and hospitalised patients, also described in others recent outbreaks $[2,13,14]$. Despite the existing recommendations for HCWs to be vaccinated against measles, we found among clusters in NA that vaccination coverage of HCWs remained insufficient. Systematic checks and updating of the vaccination status of HCWs and implementation of other control measures are needed to avoid nosocomial measles transmissions, which may have been a main transmission route in this outbreak.

The high proportion of hospitalised cases could suggest that severe cases are more likely to be reported than less severe cases diagnosed by general practitioners (GPs). During the 2008-11 epidemic, a cross-sectional survey conducted among blood donors 18-32 years 
Characteristics of clusters identified in Nouvelle-Aquitaine region, France, 30 October 2017-1 July 2018, (n = 176)

\begin{tabular}{|c|c|c|c|c|c|c|c|}
\hline \multirow[t]{2}{*}{ Clusters } & \multirow{2}{*}{$\begin{array}{l}\text { Number of } \\
\text { cases }\end{array}$} & \multirow{2}{*}{$\begin{array}{l}\text { Week of rash } \\
\text { onset of the } \\
\text { first case }\end{array}$} & \multirow{2}{*}{$\begin{array}{l}\text { Number of weeks } \\
\text { between the first } \\
\text { and the last case }\end{array}$} & \multirow{2}{*}{$\begin{array}{l}\text { Median age } \\
\quad \text { (range) }\end{array}$} & \multicolumn{2}{|c|}{$\begin{array}{c}\text { Number of } \\
\text { non-vaccinated }\end{array}$} & \multirow{2}{*}{$\begin{array}{c}\text { Number of } \\
\text { hospitalisations }\end{array}$} \\
\hline & & & & & $\mathrm{N}$ & $\%$ & \\
\hline \multicolumn{8}{|l|}{ Hospital } \\
\hline University of Bordeaux ${ }^{b}$ & 40 & $46-2017$ & 19 & $20(17-31)$ & 33 & 100 & 8 \\
\hline University of Poitiers & 21 & $09-2018$ & 7 & $20(18-55)$ & 11 & 65 & 2 \\
\hline \multicolumn{8}{|l|}{ Healthcare facilities } \\
\hline Hospital in Bordeaux ${ }^{c}$ & 26 & $48-2017$ & 20 & $26(0-72)$ & 10 & 62 & 7 \\
\hline Hospital in Poitiers & 6 & $05-2017$ & 1 & $31.5(28-36)$ & 4 & 80 & 2 \\
\hline \multicolumn{8}{|c|}{ Place assigned for France's nomadic minorities } \\
\hline Area 1 in Gironde & 8 & $52-2017$ & 12 & $18.5(1-29)$ & 7 & 100 & 4 \\
\hline Area 2 in Gironde & 3 & $06-2018$ & 2 & $3(1-21)$ & 3 & 100 & 1 \\
\hline Area 3 in Gironde & 10 & $08-2018$ & 7 & $20(0-28)$ & 5 & 83 & 2 \\
\hline Area 4 in Gironde & 3 & $07-2018$ & 3 & $10(0-26)$ & 3 & 100 & 0 \\
\hline Area 1 in Vienneb & 9 & $03-2018$ & 3 & $16(1-49)$ & 5 & 100 & 7 \\
\hline Area 2 in Vienne & 7 & $04-2018$ & 4 & $29(10-35)$ & 2 & 100 & 3 \\
\hline Area 1 in Deux-Sèvres & 3 & $05-2018$ & 4 & $7(2-8)$ & NA & NA & 2 \\
\hline Area 2 in Deux-Sèvres ${ }^{b}$ & 6 & $07-2018$ & 6 & $2(1-24)$ & 5 & 100 & 0 \\
\hline Area 3 in Deux-Sèvres & 3 & $04-2018$ & 2 & $2(0-6)$ & 2 & 100 & 0 \\
\hline \multicolumn{8}{|l|}{ Private school } \\
\hline Private school of Bordeaux & 5 & $01-2018$ & 1 & $5(4-8)$ & 5 & 100 & 0 \\
\hline Private school of Vienne $^{d}$ & 9 & $11-2018$ & 3 & $5(1-38)$ & 9 & 100 & 1 \\
\hline $\begin{array}{l}\text { Private school of } \\
\text { Deux-Sèvres }\end{array}$ & 5 & $12-2018$ & 5 & $11(7-34)$ & 4 & 80 & 1 \\
\hline \multicolumn{8}{|l|}{ Socially vulnerable people } \\
\hline Migrants & 3 & $12-2018$ & 2 & $27(26-45)$ & 2 & 100 & 1 \\
\hline Prisoners & 6 & $13-2018$ & 6 & $36(30-43)$ & 2 & 100 & 0 \\
\hline \multicolumn{8}{|l|}{ Childcare centre } \\
\hline $\begin{array}{l}\text { Childcare centre in } \\
\text { Bordeaux }\end{array}$ & 3 & $09-2018$ & 6 & $0(0-1)$ & 3 & 100 & 1 \\
\hline
\end{tabular}

NA: not available.

Source: Santé publique France.

a Number of unvaccinated or vaccinated with one dose MMR among with a known vaccination status.

${ }^{\mathrm{b}}$ One epidemiologically linked case lived in another region (not included).

' Vaccination coverage survey conducted among medical staff in Bordeaux University Hospital during the outbreak (in units with high-risk of transmission as emergency, paediatrics, infectious diseases, etc.) estimated a vaccination coverage of $14 \%$ for one MMR dose and $34 \%$ for two MMR doses.

${ }^{d}$ Eight epidemiologically linked cases lived in another region (not included).

old in the south-east of France found that only $45 \%$ of cases had been notified [15]. Further, during the first weeks of this outbreak, investigations indicated that some of the GPs waited for a laboratory confirmation before notifying the cases. This delay in reporting might have led to a delay in the implementation of control measures and further transmission of disease.

\section{Conclusion}

This measles outbreak was the consequence of a suboptimal vaccination coverage in children and insufficient catch-up vaccinations in young adults, resulting in a large reservoir of susceptible individuals. There is an urgent need to improve vaccination coverage with two doses of MMR in NA and France, especially among young adults and in hard-to-reach populations. In 2018, a new law has been enacted that makes MMR vaccination mandatory for the new birth cohorts, which should help reaching the vaccination target of $95 \%$ in the future [16]. Prevention of measles transmission in healthcare settings should be strengthened by implementing effective infection control practices and ensuring that all HCWs are immune against measles.

\section{Acknowledgements}

We thank the clinicians, biologists, and public health professionals who contributed to the development of this surveillance and the implementation of control measures; and Christian Winter for his careful reading of this manuscript. 


\section{Conflict of interest}

None declared.

\section{Authors' contributions}

Anne Bernadou was the primary investigator and drafted of the manuscript; Cyril Astrugue, Fatima Aït-Belghiti, Denise Antona and Stéphanie Vandentorren provided epidemiological support during the outbreaks; Julia Dina conducted microbiology investigation; Matthieu Méchain, Valérie Le Galliard, Catherine Verdun-Esquer and France Dupuy were responsible for management of patients. All authors reviewed and approved the final version of the manuscript.

\section{References}

1. Houssin D, Brücker G. Rougeole: déclaration obligatoire et nouvelles mesures vaccinales. Bull Epidemiol Hebd2005; 41-42:205-12.

2. Antona D, Lévy-Bruhl D, Baudon C, Freymuth F, Lamy M, Maine C, et al. Measles elimination efforts and 2008-2011 outbreak, France. Emerg Infect Dis. 2013;19(3):357-64. https://doi. org/10.3201/eid1903.121360 PMID: 23618523

3. Haut Conseil de la Santé publique (HCSP). Calendrier des vaccinations et recommandations vaccinales 2018 [Schedule of vaccinations and vaccination recommendations 2018]. Paris: HCSP; 2018. French. Available from: http://solidarites-sante. gouv.fr/IMG/pdf/calendrier_vaccinations_2018.pdf

4. Ministère de la santé et des sports. CIRCULAIRE NDGS/ $\mathrm{Rl} 1 / 2009 / 334$ du 4 novembre 2009 relative à la transmission obligatoire de données individuelles à l'autorité sanitaire en cas de rougeole et la mise en œuvre de mesures préventives autour d'un cas ou de cas groupés. [CIRCULAR N ${ }^{\circ}$ DGS / RI1 / $2009 / 334$ of 4 November 2009 on the compulsory transmission of individual data to the health authority in case of measles and the implementation of preventive measures around a case or a cluster]. Code de la santé publique (04/11/2009). French. Available from: http://solidarites-sante.gouv.fr/IMG/ pdf/o9 334topdf.pdf

5. European Centre for Disease Prevention and Control (ECDC) Monthly measles and rubella monitoring report July 2018. Stockholm: ECDC; 2018. Available from: https://ecdc.europa. eu/sites/portal/files/documents/Monthly-Measles-Rubellamonitoring-report-July-2018-1.pdf

6. Santé Publique France(ANSP). Bulletin épidémiologique rougeole. Données de surveillance au 27 juin 2018[Epidemiological Bulletin Measles. Monitoring Data as of June 27, 2018]. Saint-Maurice: ANSP; 2018. French. Available from: http://invs.santepubliquefrance.fr/ Dossiers-thematiques/Maladies-infectieuses/Maladies a-prevention-vaccinale/Rougeole/Points-d-actualites/ Bulletin-epidemiologique-rougeole.-Donnees-de-surveillanceau-27-juin-2018

7. Sá Machado R, Perez Duque M, Almeida S, Cruz I, Sottomayor A, Almeida I, et al. Measles outbreak in a tertiary level hospital, Porto, Portugal, 2018: challenges in the postelimination era. Euro Surveill. 2018;23(20):18-00224. https:// doi.org/10.2807/1560-7917.ES.2018.23.20.18-00224 PMID: 29790461

8. Hahné SJM, Nic Lochlainn LM, van Burgel ND, Kerkhof J, Sane J, Yap KB, et al. Measles Outbreak Among Previously Immunized Healthcare Workers, the Netherlands, 2014. J Infect Dis. 2016;214(12):1980-6. https://doi.org/10.1093/infdis/jiw480 PMID: 27923955

9. Santé publique France (ANSP). Bulletin de santé publique Nouvelle-Aquitaine. Vaccination [NouvelleAquitaine Public Health Bulletin. Vaccination]. Bordeaux: ANSP; 2018. French. Available from: http://invs. santepubliquefrance.fr/fr/Publications-et-outils/Bulletinde-veille-sanitaire/Tous-les-numeros/Nouvelle-Aquitaine/ Bulletin-de-sante-publique-Nouvelle-Aquitaine.-Avril-2018

10. World Health Organization (WHO). Global measles and rubella strategic plan: 2012. Geneva: WHO; 2012. Available from: http://apps.who.int/iris/bitstream/hand le/10665/44855/9789241503396_eng.pdf?sequence $=1$

11. European Centre for Disease Prevention and Control (ECDC). Risk of measles transmission in the EU/EEA, 21 March 2018. Stockholm: ECDC; 2018. Available from: https://ecdc. europa.eu/sites/portal/files/documents/Measles-rapid-riskassessment-European-Union-countries.pdf
12. Béraud G, Abrams S, Beutels P, Dervaux B, Hens N. Resurgence risk for measles, mumps and rubella in France in 2018 and 2020. Euro Surveill. 2018;23(25):1700796. https:// doi.org/10.2807/1560-7917.ES.2018.23.25.1700796 PMID: 29945697

13. Filia A, Bella A, Del Manso M, Baggieri M, Magurano F, Rota MC. Ongoing outbreak with well over 4,000 measles cases in Italy from January to end August 2017 - what is making elimination so difficult? Euro Surveill. 2017;22(37):30614. https://doi.org/10.2807/1560-7917.ES.2017.22.37.30614 PMID: 28933342

14. Grammens T, Schirvel C, Leenen S, Shodu N, Hutse V, Mendes da Costa E, et al. Ongoing measles outbreak in Wallonia, Belgium, December 2016 to March 2017: characteristics and challenges. Euro Surveill. 2017;22(17):30524. https://doi. org/10.2807/1560-7917.ES.2017.22.17.30524 PMID: 28488998

15. Antona D, Gallian P, Gimeno L, Fonteneau L, Jacquot C, Morel $P$, et al. Enquête de séroprévalence rougeole-rubéole chez les donneurs de sang, France, 2013 [Measles-rubella seroprevalence survey in blood donors, France, 2013]. Jounées nationales infectieuses; 2015 June 10-12, Nancy. French. Available from: http://www.infectiologie.com/UserFiles/File/ medias/JNI/JNI15/posters/2015-poster-JNI-PADS01-07.pdf

16. Ministère des solidarités et de la santé. Article L3111-2, L3111-2. Code de la santé publique (01/01/2018) [public health code (01/01/2018)]. French. Available from: https://www.legifrance. gouv.fr/affichCodeArticle.do?cidTexte=LEGITEXTo0000607266 5\&idArticle $=$ LEGIARTIoo0006687781

\section{License and copyright}

This is an open-access article distributed under the terms of the Creative Commons Attribution (CC BY 4.0) Licence. You may share and adapt the material, but must give appropriate credit to the source, provide a link to the licence, and indicate if changes were made.

This article is copyright of the authors or their affiliated institutions, 2018. 